\title{
The Cochrane Schizophrenia Group
}

\author{
Clive Adams ${ }^{1}$, Lorna Duggan ${ }^{2}$, Kristian Wahlbeck ${ }^{3}$ e Paul White ${ }^{4}$
}

\begin{abstract}
The Cochrane Schizophrenia Group was launched in 1994 and is now producing, maintaining and disseminating high quality systematic reviews of the effectiveness of care available for those with schizophrenia. This international Group is unearthing many fundamental gaps in knowledge that will have to be answered in pragmatic randomised controlled trials.
\end{abstract}

Keywords Systematic reviews; pragmatic randomized trials

Resumo O Cochrane Schizophrenia Group iniciou suas atividades em 1994 e agora produz, mantém e dissemina revisões sistemáticas de qualidade sobre a eficiência dos tratamentos disponíveis para pessoas com esquizofrenia. Este grupo internacional está identificando perguntas fundamentais neste campo do conhecimento, que terão que ser respondidas por meio de testes pragmáticos randomizados.

\section{Descritores Revisões sistemáticas; testes pragmáticos randomizados}

Four years ago Schizophrenia Research published an account of how the Cochrane Schizophrenia Group was initiated. ${ }^{1}$ The Group is now well established and productive. This article briefly outlines its development, current activities and future.

At the $7^{\text {th }}$ Biennial Winter Workshop on Schizophrenia 1994 (Les Diablerets, Switzerland) a few people met to confirm their interest in working together to systematically review all randomised controlled trials relevant to the care of those with schizophrenia. This small meeting was the start of the vibrant global network, the Cochrane Schizophrenia Group, working within the Cochrane Collaboration. The Collaboration itself was established in 1993 in order to produce, maintain and disseminate systematically conducted reviews of health care interventions. ${ }^{2,3}$

The Cochrane Schizophrenia Group had three founding editors (Clive Adams - University of Oxford, UK; Jeremy Anderson - University of Melbourne, Australia; Jair Mari Universidade Federal de São Paulo, Brazil), high-grade administrative support and little else except energy and commitment. Now the four editors (see authorship) work with an administrator/co-ordinator (Leanne Roberts) and reviewers world-wide. The Cochrane Schizophrenia Group aims to: a) identify, and make accessible, citations to every randomised controlled trial involving those with schizophrenia, chronic/ serious mental illnesses or psychoses; and b) produce and maintain systematically conducted reviews relevant to this participant group.

The Cochrane Schizophrenia Group's systematic reviews are characterised by a priori definition of objectives, search strategies, inclusion criteria, data collection procedures and means of data assimilation. This protocol forms the first stage of the review. The protocols are then published to allow for peer or consumer input before the full work is undertaken.

All reviews are based on extensive literature searches. Great efforts have already gone into identifying published and unpublished work. Currently the Register of studies, maintained by the Cochrane Schizophrenia Group, contains about 4,000 randomised controlled trials dating from 1948 to the present day. These have been found by methodical electronic searching, and by hand searching of journals and conference proceedings. A survey of the quality and content of these studies over time is in its final stages.

In order to avoid publication bias ${ }^{4}$ all trials that are unpublished must also be identified and systematic reviews need to be based on as high a proportion as possible of relevant

1. Co-ordinating Editor - Cochrane Schizophrenia Group.

2. Criticism Editor - Malborough House Milton Keynes Community Trust.

3. Editor - University of Helsinki Department of Psychiatry.

4. Editor Clinical Studies - Unit Wolston Park Hospital Wolston.

Rev Bras Psiquiatr, 21 (2), 1999 
studies. Because of the potentially important health care consequences of excluding relevant unreported trials, many of the world's major medical journals, including the BMJ, The Lancet, and Annals of Internal Medicine, have joined together in calling an amnesty for unpublished trials. The amnesty was launched on 19 September 1997 at the International Congress on Biomedical Peer Review in Prague. Certainly those with unpublished work are welcome to contact any of the authors of this paper with details of their studies.

The conclusions within the reviews produced by the Cochrane Schizophrenia Group avoid, where possible, personal opinion or consensus. The completed reviews are also subjected to peer and consumer input and are published on The Cochrane Library. This is a CD-ROM that is issued quarterly (The Cochrane Library 1996). ${ }^{5}$ As new data come to light reviews are updated.

The Cochrane Collaboration does not focus on mental health issues alone ${ }^{2}$ and the Cochrane Library now contains more than 300 maintained reviews on all aspects of healthcare. The Cochrane Schizophrenia Group is a highly productive Group and maintained reviews of new medications, old drugs, psychosocial treatments and care policies are all available. There are no less than nine reviews of the management of tardive dyskinesia. Abstracts of all reviews are freely available on the Internet (http://archie.cochrane.co.uk/info/abstracts/ abidx.htm) and the full list of protocols and reviews maintained by the Group are given at the end of this article (appendix 1).

The network of reviewers that the Cochrane Schizophrenia Group has established is extensive and covers all continents. The editors, along with the wider Cochrane Collaboration, provide all training and mentoring for those new to this type of work. Extensive training materials are also available, as is software for the task. The Cochrane Schizophrenia Group is not a "closed shop". It is open to anyone - clinician, researcher, recipient of care - who really wants to take a step back from what is stated to be known about the value of care and to look dispassionately on what data are really there.

In short, these reviews represent a genuine step forward for those tired of the traditional approach to evaluation of care - an approach that depends so heavily on consensus, individual opinion or rhetoric from the pharmaceutical industry. The maintained systematic reviews within the Cochrane Library make every effort to summarise and quantify all of the best available data relating to treatment efficacy. The reviews are open to criticism and there is an established mechanism by which valid comment is taken into account and amendments made.

The Cochrane Schizophrenia Group has much to do before it can say that all trial evidence as regards the care of those with schizophrenia is systematically reviewed and made widely available to a general readership. Many everyday treatments given to those with schizophrenia do not, as yet, have an upto-date quantitative summary of all relevant trial evidence. Often, even when the review is done, there is no definitive answer to questions about effectiveness. Many more, good quality randomised trials are needed.

However, explanatory trials dominate the schizophrenia literature. This type of study may answer questions such as, "can it work?" The question "does it work in every day practice?" is often unanswered. ${ }^{6}$ Explanatory studies often include participants with operationally defined illnesses and are performed in strictly controlled conditions. Generalisability of any valid results may therefore be poor. To complicate matters further the interventions within explanatory trials may not even be widely accessible and outcomes are often measured by scales that even researchers do not fully understand.

Although explanatory trials are necessary for drug regulatory boards they add to clinical complexity rather than detract. Pragmatic trials, based on the foundation of good systematic reviews, aim to simplify clinical practice whilst answering crucial questions. These studies include participants who would be recognisable in every day practice - for example those with schizophrenia as diagnosed by standard clinical acumen rather than by operational criteria. People within a pragmatic trial are allocated at random to treatments that are widely accessible and clinically relevant. Outcomes are recorded in clear and simple terms. $^{7}$ The Cochrane Schizophrenia Group hopes to initiate a global Schizophrenia Pragmatic Trials Network in 1998 in order to start randomised studies in the following year.

\title{
Appendix 1 - Reviews and review protocols of the Cochrane Schizophrenia Group
}

\author{
Reviews \\ - Anticholinergic medication for neuroleptic-induced tardive dyskinesia. Soares KVS and McGrath JJ. \\ - Antilibidinal management for disorders of sexual preference and convicted sexual offenders. White P, Bradley C, and Ferriter M. \\ - Antipsychotic medication for challenging behaviour in people with learning disability. Brylewski J and Duggan L. \\ - Antipsychotic medication for those with both schizophrenia and learning disability. Duggan L and Brylewski J. \\ - Assertive Community Teams for schizophrenia. Marshall M and Lockwood A. \\ - Benzodiazepines for neuroleptic-induced tardive dyskinesia. McGrath JJ and Soares KVS. \\ - Beta-blocking supplements to standard medication for schizophrenia. Ahonen J, Cheine M, and Wahlbeck K. \\ - Calcium-channel blockers for neuroleptic-induced tardive dyskinesia. Soares KVS and McGrath JJ. \\ - Case management for severe mental disorders. Marshall M, Gray A, Lockwood A, and Green R. \\ - Chlorpromazine versus placebo for schizophrenia. Thornley B, Adams CE, and Awad G. \\ - Cholinergic medication for neuroleptic-induced tardive dyskinesia. McGrath JJ and Soares KVS. \\ - Clozapine vs 'typical' neuroleptic medication for schizophrenia. Wahlbeck K, Cheine M, Essali MA, and Rezk E.
}


- Community mental health team management for severe mental illnesses and disordered personalities. Tyrer P, Coid J, Simmonds $\mathrm{S}$, Joseph P, and Marriott S.

- Depot versus oral fluphenazine for schizophrenia. Adams CE and Eisenbruch M.

- Electroconvulsive therapy for schizophrenia. Tharyan P and Seifas R.

- Family intervention for schizophrenia. Mari JJ and Streiner D.

- GABA agonist medication for those with neroleptic-induced tardive dyskinesia. Soares KVS, McGrath JJ, and Deeks JJ.

- Intercessory prayer for the alleviation of ill health and the promotion of good health. Roberts L, Ahmed I, Sargent C, and Hall S.

- Long versus short term hospitalization for schizophrenia. Johnstone P and Zolese G.

- Neuroletic-induced tardive dyskinesia: efficacy of vitamin E. Soares KVS and McGrath JJ.

- Neuroleptic-induced tardive dyskinesia: miscellaneous treatments. McGrath JJ and Soares KVS.

- Neuroleptic reduction or cessation and the value of neuroleptics as specific treatments for those with neuroleptic-induced tardive dyskinesia. McGrath JJ and Soares KVS.

- Risperidone for schizophrenia. Kennedy E, Song F, Hunter R, and Gilbody S.

- Zuclopenthixol acetate in the treatment of acute symptoms of serious mental illnesses. Fenton M, Coutinho E, and Campbell C.

\section{Protocols of reviews soon to be completed}

- Clozapine vs newer 'atypicals' for schizophrenia. Tuunainen A.

- Cognitive behavioural therapy in schizophrenia. Jones C, Cormack I, da Mota JIS, and Campbell C.

- Cognitive rehabilitation in schizophrenia. Hayes R and McGrath J.

- Crisis intervention for schizophrenia. Joy C, Adams CE, Rice K.

- The effectiveness of day hospital treatment for psychiatric disorders. Almaraz-Serrano AM, Marshall M, and Creed F.

- Life skills programmes for chronic mental illnesses. Robertson L, Connaughton JA, and Nicol MM.

- Neuroleptic-induced tardive dyskinesia: non-neuroleptic medications that impact on dopamine and noradrenaline. Soares KVS and McGrath JJ.

- Olanzapine for schizophrenia. Dardennes R, Indran S, and El-Dosoky A.

- Quetiapine for schizophrenia. Srisurapanont M, Disyavanish C, and Taimkaew K.

- Substance misuse and severe mental illness. Jeffery D, McLaren S, Ley A, and Seigfried N.

- Supported housing for people with severe mental disorder. Hayes AA and Macdonald GM.

\section{References}

1. Cochrane Collaboration Schizophrenia Review Group. (1994) Schizophrenia and the Cochrane Collaboration. Schizophr. Res. 13, 185-188.

2. Chalmers I, Dickersin K, Chalmers TC . Getting to grips with Archie Cochrane's agenda. BMJ 1992;305:786-8.

3. Chalmers I. The Cochrane collaboration: preparing, maintaining, and disseminating systematic reviews of the effects of health care. Ann N Y Acad Sci 1993;703:156-63.

4. Dickersin K, Min YI. Publication bias: the problem that won't go away. Ann N Y Acad Sci 1993;703:135-46.

5. The Cochrane Library. The Cochrane Collaboration [database on disk and CD-rom]. 1996.

6. Roland $\mathrm{M}$, Torgerson DJ. What are pragmatic trials? BMJ 1998;316:285.

7. Sutherland I. The design of records and follow up. In: Bradford Hill A, editor. Controlled Clinical Trials. Oxford: Blackwell; 1960. p. 151-4.

\section{Correspondence}

Clive Adams

Summertown Pavilion

Middle Way

Oxford OX2 7LG - UK.

Tel: +44 1865316776

Fax:+441865316023

email: clive.adams@psych.ox.ax.uk 